\title{
Mental Health Services in South Africa: Scaling up and future directions
}

\author{
K Sorsdahl, DJ Stein, C Lund \\ Department of Psychiatry \& Mental Health, University of Cape Town, Cape Town, South Africa
}

\begin{abstract}
"No health without mental health" has become a rallying call for the World Health Organization and numerous service providers, training institutions, health researchers, and advocacy groups around the world. It is timely to consider the implications of this call for South Africa. We review key evidence regarding the burden and risk factors for mental disorders in South Africa and crucial challenges for local mental health services and research. We emphasize that mental disorders are more impairing but less treated than physical disorders, and that existing services need to be scaled up and adapted to the local context. New research is needed to determine what interventions work best in the South African context.
\end{abstract}

Keywords: Mental Health; Health; South Africa; Services

Received: 27-03-2012

Accepted: $28-03-2012$

doi: http://dx.doi.org/10.4314/ajpsy.v15i3.21

\section{Introduction}

"No health without mental health" has become a rallying call for the WHO and numerous service providers, training institutions, health researchers, and advocacy groups around the world. ${ }^{1}$ This pithy statement captures several issues: the growing contribution of mental disorders to the global burden of disease ${ }^{2}$, the availability of efficacious and cost-effective treatments ${ }^{3}$, the high level of comorbidity between "physical" and "mental" illness ${ }^{4}$ and the need to achieve parity for mental health services as a basic human right for people living with mental illness. ${ }^{5}$

With the current movement for global mental health, it is timely to review these issues from a South African perspective. Are mental disorders important in our particular context and do they deserve additional resourcing? If we agree that services need scaling up, what adaptations are needed within our context? Finally, what is the most important mental health services research to conduct going forward?

\section{Priority Conditions}

Global surveys of mental disorders and a range of studies in South Africa have increasingly demonstrated the high prevalence, chronicity, and morbidity of these conditions. ${ }^{6}$ Nevertheless it is only recently that representative data in the form of the South African Stress \& Health Study (SASH) become available. SASH was undertaken as part of the World Mental

\section{Correspondence}

Dr K Sorsdahl

Department of Psychiatry and Mental Health, J-Block Groote Schuur

Hospital, Observatory, Cape Town, South Africa

email: katherine.sorsdahl@uct.ac.za
Health Surveys ${ }^{7}$ and consisted of comprehensive structured interviews with 4351 South African adults administered in several languages. ${ }^{8}$

One of the primary goals of SASH was to determine the burden of mental disorders by assessing the prevalence and severity of specific psychiatric disorders and patterns of service use. ${ }^{9}$ For example, 12 -month prevalence data indicated that $16.5 \%$ of adults have suffered a common mental disorder in the past year ${ }^{10}$, but that only $25 \%$ of these individuals had received treatment during this time. ${ }^{11}$ Furthermore, although mental disorders are significantly more disabling than physical disorders, they are 10 times less likely to be treated. ${ }^{12}$

The SASH data also emphasize the importance of a number of key risk factors for mental disorders. In particular, a number of papers have emphasized the link between trauma and common mental disorders. ${ }^{13}$ Although SASH did not inquire about HIV status, it did provide some data indicating the importance of the link between HIV and mental disorder. ${ }^{14}$ In the South African context, food insufficiency was found to be a key risk factor for mental disorder ${ }^{15}$, and low socio-economic status was shown to be an independent risk factor for psychological distress. ${ }^{16}$

SASH data are consistent with a range of data from other local studies. First, South African morbidity data indicate that mental disorders are the 3rd highest contributor to the local burden of disease, after HIV and other infections disorders. ${ }^{17}$ Second, interpersonal violence is highly prevalent in South Africa, and is associated with major psychiatric morbidity. ${ }^{18-20}$ Third, both HIV and substance use have extremely important associations with mental disorder in our context. ${ }^{21,22}$ Fourth, there are major links between poverty and mental illness, mediated by a range of factors other than food insufficiency. ${ }^{23}$ 


\section{The Scaling up of Services}

Given these findings, an obvious conclusion is that there is a need to establish parity for mental health services in South Africa, to use existing human and infrastructure resources as efficiently as possible, and to develop additional resources over time. The growing evidence for the efficacy and cost-effectiveness of both pharmacotherapeutic and psychotherapeutic interventions for mental disorders ${ }^{24,25}$, and emerging evidence that treating mental disorders can carry economic benefits at the individual and household level26, provides persuasive arguments for such shifts. In addition, there is growing recognition of parity for mental health services as a human rights issue ${ }^{27}$ In considering how best to achieve parity for mental health, and how optimally to scale up services, an immediate issue is the current status of mental health policy, legislation and systems in South Africa. The Mental Health and Poverty Project (MHaPP) has emphasized that there are major gaps in current services and policies. ${ }^{28,29}$

The mental health Gap Action Programme (mhGAP) is the WHO's action plan to scale up services for mental, neurological, and substance use disorders, and provides a set of practical clinical guidelines and algorithms for the delivery of mental health care by general health providers (doctors and nurses) ${ }^{30}$ For example, the most appropriate package of treatment for attention-

deficit/hyperactivity disorder (ADHD) in low- and middle-income countries (LMICs) should comprise screening high-risk groups, psycho-educational interventions, pharmacotherapy, and behavioural interventions. ${ }^{31} \mathrm{~A}$ key construct advocated by the WHO in scaling up services in resource constrained contexts is that of task shifting. The concept of task shifting has, for example, been advocated by the WHO to increase access to ARVs and HIV services. ${ }^{32}$ Task shifting is defined as "delegating tasks to existing or new cadres with either less training or narrowly tailored training", ${ }^{33}$ Task-shifting may be a viable option to deliver mental health interventions in primary care and community based programs particularly in resource-constrained environments ${ }^{34}$, and should ideally also be accompanied by development of more highly trained personnel to provide support and supervision. ${ }^{35}$

\section{Adaptation of Services to the South African Context}

In scaling up services, it is vital that interventions are socially and culturally appropriate. The mhGAP provides guidelines for care, but at the same time indicates that countries must adapt interventions to their own contexts. A major issue is therefore whether interventions developed elsewhere are in fact effective and cost-effective in contexts such as South Africa. The available South African literature highlights a number of factors that should be considered when designing and implementing these interventions. Here we consider the importance of how best to integrate packages of mental health care into routine primary health care; how best to employ traditional healers; how to improve low mental health literacy; and how to address the negative impact of stigma.

First, while there is growing evidence on "what" interventions work in other countries ${ }^{23}$, there is less evidence on both efficacy and effectiveness in South Africa. van't Hof and colleagues reviewed the literature on psychotherapy trials in low and middle income countries, and noted that there is some evidence for efficacy. ${ }^{36} \mathrm{~A}$ number of preliminary effectiveness studies in South Africa show promise, including the treatment of depression by community workers using interpersonal therapy in primary care ${ }^{37}$ and a multimedia-supported adherence tools administered by lay counsellors for ARV adherence. ${ }^{38}$ Data on efficacy and effectiveness of packages of care for priority mental disorders are important for the primary care revitalisation programme of the South African Department of Health.

Second, several studies have emphasized that traditional healers may play an important role in addressing mental health care needs in South Africa by offering culturally appropriate treatment. ${ }^{39-41}$ In many traditional African belief systems, mental health problems are perceived as due to ancestors or bewitchment, and traditional healers and religious advisors are viewed as having expertise in these areas. ${ }^{42}$ A nationally representative sample of adults found that $9 \%$ of the respondents consulted traditional healers and $11 \%$ consulted a religious or spiritual advisor for their mental health care needs. ${ }^{43}$ Use of traditional healers was predicted by having an anxiety or a substance use disorder. Although a few studies have shown the potential of traditional medicine ${ }^{44}$, some traditional healers' practices have been found to be perilous. ${ }^{45}$ Equipping traditional healers to understand and effectively manage mental disorders in their communities may contribute towards scaling up services.

Third, one of the most significant barriers to accessing care for people with a mental disorder in South Africa is low mental health literacy, defined as "knowledge and beliefs about mental illness that aid their recognition, management or prevention". ${ }^{46}$ In a study investigating barriers to treatment in a nationally representative study in South Africa, the most common reason for not accessing mental health services was a low perceived need for treatment (93\%). ${ }^{47}$ Mental health literacy in South Africa has been investigated in community samples ${ }^{48,49}$, and in an HIV population. ${ }^{50}$ This work indicates that common mental disorders are viewed as the result of everyday life challenges, rather than as treatable conditions. However, there is some evidence (none from South Africa) to suggest that population-wide and individual level interventions designed to improve mental health literacy are effective. ${ }^{51}$ A mental health literacy component may be integral to developing local interventions. ${ }^{52}$

Fourth, stigma is another barrier to scaling up services for people with mental disorders. ${ }^{53} \mathrm{~A}$ few studies have, for example, investigated community attitudes towards the mentally ill in the South African context. ${ }^{54,55}$ Compared to an average person, those with a mental disorder are viewed as being more unpredictable, tense and dangerous, worthless, delicate, slow, weak, dirty, and foolish. ${ }^{56}$ Furthermore, in a study investigating the attitudes South Africans have toward people with specific psychiatric disorders (schizophrenia, substance use, post-traumatic stress disorder and depression), results found more stigmatizing attitudes toward patients with substance abuse and schizophrenia than other disorders. ${ }^{57}$ Thus, there is an urgent need to implement effective strategies to reduce stigma. While a number of anti-stigma campaigns and activities have been conducted locally ${ }^{80 ; 59}$, the effectiveness of these activities requires better assessment. ${ }^{60}$

\section{Future Research}

Lund and Petersen ${ }^{27}$ have recently reviewed mental health services research in South Africa and concluded that research should focus on intervention and economic evaluations of packages of care adapted for the South African context. However, as indicated above, South Africa's rich cultural diversity poses significant challenges when adapting Western diagnostic conventions, research tools and psychosocial interventions. Great care in programme design, training of non-specialists, implementation and research is required.

First, it is important to undertake intervention research on priority mental disorders that have been shown to be highly prevalent and disabling. Investigating how useful screening tools are for the 
detection of priority disorders and which psychosocial interventions are the most acceptable to patients and produce the best outcomes, would prove useful for scaling up services. ${ }^{61}$

Second, it is important to assess whether adaptations of interventions for delivery by non-specialists in the local context proves feasible and effective. Investigating whether or not various types of non-specialists have the ability to deliver evidence based intervention, and retain fidelity to treatment guidelines would also be useful. There is also need for greater work locally on the most effective way to training non-specialist health workers to deliver mental health care. ${ }^{62}$

Third, it is important to discover the best way to address the high levels of trauma and interpersonal violence in the country.63:64 One hypothesis is that if prevention and management services were integrated into the health system, they might be more effective, through screening, brief interventions and referral to treatment where necessary. Interventions developed to address substance use may also be important from a prevention and promotion perspective.

Finally, it is important to undertake additional research in the crucial areas of substance use ${ }^{65}$ disorders and HIV/AIDS. ${ }^{66}$ Each of these is a vitally important area in their own right in the South African context, and they also intersect in important ways. ${ }^{67}$ Research on preventive interventions, as well as on effective treatments for individuals suffering from substance use disorders and from neuroHIV/AIDS is urgently needed in the South African context.

\section{Conclusions}

In this paper we have emphasized that local data on burden of disease confirms the crucial importance of mental disorders, that mental health services urgently need to be scaled up, that such services need to be carefully adapted with the local context in mind, and that further work is needed to determine what interventions work best in the South African context. Although further research is needed, our hope is that over the next decades much will be learned about how to provide evidence-based, cost-effective, feasible and acceptable interventions in the South African context, and the political will can be found to implement such interventions.

\section{Acknowledgements}

Dan Stein is supported by the Medical Research Council of South Africa. Crick Lund is supported by a grant from the Department for International Development (DFID), the PRogramme for Improving Mental health carE (PRIME). The opinions expressed in this article are not necessarily those of DFID.

\section{References}

1. Prince M, Patel V, Saxena S, Maj M, Maselko J, Phillips MR et al. No health without mental health. Lancet 2007; 370(9590):859-877.

2. Mathers CD, Loncar D. Projections of global mortality and burden of disease from 2002 to 2030. PLoS Med 2006; 3(11):e442.

3. Patel V, Araya R, Chatterjee S, Chisholm D, Cohen A, De SM et al. Treatment and prevention of mental disorders in low-income and middle-income countries. Lancet 2007; 370(9591):991-1005.

4. Prince M, Patel V, Saxena S, Maj M, Maselko J, Phillips MR et al. No health without mental health. Lancet 2007; 370(9590):859-877.

5. WHO. WHO Resource book on mental health, human rights and legislation. 2005. Geneva, WHO.

6. Demyttenaere K, Bruffaerts R, Posada-Villa J, Gasquet I, Kovess V, Lepine JP et al. Prevalence, severity, and unmet need for treatment of mental disorders in the World Health Organization World Mental Health Survey. JAMA 2004; 291(21):2581-2590.
7. Kessler RC, Ustun TB. The WHO World Mental Health Surveys: Global Perspectives on the Epidemiology of Mental Disorders. 2008. New York, Cambridge University Press.

RefType: Report

8. Williams DR, Herman A, Kessler RC, Sonnega J, Seedat S, Stein DJ et al. The South Africa Stress and Health Study: rationale and design. Metab Brain Dis 2004; 19(1-2):135-147.

9. Williams DR, Herman A, Kessler RC, Sonnega J, Seedat S, Stein DJ et al. The South Africa Stress and Health Study: rationale and design. Metab Brain Dis 2004; 19(1-2):135-147.

10. Williams DR, Herman A, Stein DJ, Heeringa SG, Jackson PB, Moomal H et al. Twelve-month mental disorders in South Africa: prevalence, service use and demographic correlates in the population-based South African Stress and Health Study. Psychol Med 2008; 38(2):211-220.

11. Seedat S, Stein DJ, Herman A, Kessler R, Sonnega J, Heeringa S et al. Twelvemonth treatment of psychiatric disorders in the South African Stress and Health Study (World Mental Health Survey Initiative). Soc Psychiatry Psychiatr Epidemiol 2008; 43(11):889-897.

12. Suliman S, Stein DJ, Myer L, Williams DR, Seedat S. Disability and treatment of psychiatric and physical disorders in South Africa. J Nerv Ment Dis 2010; 198(1):8-15.

13. Fincham D, Grimsrud A, Corrigall J, Williams DR, Seedat S, Stein DJ et al. Intermittent explosive disorder in South Africa: prevalence, correlates and the role of traumatic exposures. Psychopathology 2009; 42(2):92-98.

14. Myer L, Stein DJ, Grimsrud AT, Herman A, Seedat S, Moomal H et al. DSMIV-defined common mental disorders: association with HIV testing, HIV-related fears, perceived risk and preventive behaviours among South African adults. S Afr Med J 2009; 99(5 Pt 2):396-402.

15. Sorsdahl K, Slopen N, Siefert K, Seedat S, Stein DJ, Williams DR. Household food insufficiency and mental health in South Africa.J Epidemiol Community Health 201 1; 65(5):426-431.

16. Myer L, Stein DJ, Grimsrud A, Seedat S, Williams DR. Social determinants of psychological distress in a nationally-representative sample of South African adults. Soc Sci Med 2008; 66(8): 1828-1840.

17. Bradshaw D, Norman R, Schneider M. A clarion call for action based on refined DALY estimates for South Africa. S Afr Med J 2007; 97(6):438, 440.

18. Norman R, Schneider M, Bradshaw D, Jewkes R, Abrahams N, Matzopoulos R et al. Interpersonal violence: an important risk factor for disease and injury in South Africa. Popul Health Metr 2010; 8:32.

19. Norman R, Bradshaw D, Schneider M, Jewkes R, Mathews S, Abrahams Net al. Estimating the burden of disease attributable to interpersonal violence in South Africa in 2000. S Afr Med J 2007; 97(8 Pt 2):653-656.

20. Doolan K, Ehrlich R, Myer L. Experience of violence and socioeconomic position in South Africa: a national study. PLoS One 2007; 2(12):el290.

21. Collins PY, Holman AR, Freeman MC, Patel V. What is the relevance of mental health to HIVIAIDS care and treatment programs in developing countries? A systematic review. AIDS 2006; 20(12):1571-1582.

22. Cluver LD, Orkin M, Gardner F, Boyes ME. Persisting mental health problems among AIDS-orphaned children in South Africa.J Child Psychol Psychiatry 2011.

23. Lund C, Breen A, Flisher AJ, Kakuma R, Corrigall J, Joska JA et al. Poverty and common mental disorders in low and middle income countries: $A$ systematic review. Soc Sci Med 2010; 71 (3):517-528.

24. Patel V, Araya R, Chatterjee S, Chisholm D, Cohen A, De SM et al. Treatment and prevention of mental disorders in low-income and middle-income countries. Lancet 2007; 370(9591):991-1005.

25. Lancet Global Mental Health Group. Scale up services for mental disorders: a call for action. Lancet 2007; 370:1241-1252.

26. Lund C, De SM, Plagerson S, Cooper S, Chisholm D, Das J et al. Poverty and mental disorders: breaking the cycle in low-income and middle-income countries. Lancet 201 1; 378(9801):1502-1514. 
27. Lund C, Stein DJ, Corrigall J, Bradshaw D, Schneider M, Flisher AJ. Mental health is integral to public health: a call to scale up evidence-based services and develop mental health research. S Afr Med J 2008; 98(6):444, 446.

28. Lund C, Kleintjes S, Kakuma R, Flisher AJ. Public sector mental health systems in South Africa: inter-provincial comparisons and policy implications. Soc Psychiatry Psychiatr Epidemiol 2010; 45(3):393-404.

29. Petersen I, Lund C. Mental health service delivery in South Africa in the past decade (2000 - 2010). One step forward, one step back. South African Medical Journal 201 1;101:751-7 201 1; 101:751-757.

30. WHO. mhGAP Intervention Guide for Mental, Neurological and Substance Use Disorders in non-specialized health settings: Mental health Gap Action Programme (mmhGAP). 2010. Geneva, WHO

Ref Type: Report

31. Flisher AJ, Sorsdahl K, Hatherill S, Chehil S. Packages of care for attentiondeficit hyperactivity disorder in low- and middle-income countries. PLOS Med 2010; 7(2):e1000235.

32. WHO. Task Shifting : Global Recommendations and Guidelines. 2007. Geneva, WHO.

33. Fulton BD, Scheffler RM, Sparkes SP, Auh EY, Vujicic M, Soucat A. Health workforce skill mix and task shifting in low income countries: a review of recent evidence. Hum Resour Health 2011 ; $9(1): 1$

34. Kakuma R, Minas H, van GN, Dal Poz MR, Desiraju K, Morris JE et al. Human resources for mental health care: current situation and strategies for action. Lancet 2011; 378(9803):1654-1663.

35. Stein DJ, Betancourt OA, Emsley RA, Jeenah Y, Mkize D, Pretorius J et al. Subspecialties in psychiatry: towards parity in mental health training and services. S Afr Med J 2009; 99(1):38-39

36. Van't Hof E, Cuijpers P, Waheed W, Stein DJ. Psychological treatments for depression and anxiety disorders in Low- and middle- income countries: a meta-analysis. African Journal of Psychiatry 2011; 14(3):200-207.

37. Petersen I, Bhana K, Baillie K. The Feasibility of Adapted Group-Based Interpersonal Therapy (IPT) for the Treatment of Depression by Community Health Workers Within the Context of Task Shifting in South Africa. Community Mental Health Journal DOI: 10 1007/s10597-01 1-9429-2 2011.

38. Rowe J, Stein D, Remien RH, Mellins CA, Abrams E, Kelsey R et al. Adapting the SMART adherence intervention for South Africa: Creating an effective multimedia-supported adherence tool for ART counselors. 2011. Presented at the Annual New York HIV Research Centers Consortium Scientific Meeting, New York, Mar 2010.

39. Ensink K, Robertson B. Patient and family experiences of psychiatric services and indigenous healers. Transcultural Psychiatry 1999; 36:23-43.

40. Mbanga NI, Niehaus DJ, Mzamo NC, Wessels CJ, Allen A, Emsley RA et al. Attitudes towards and beliefs about schizophrenia in Xhosa families with affected probands. Curationis 2002; 25(1):69-73.

41. Niehaus DJ, Stein DJ, Koen L, Lochner C, Muller JE, Mbanga NI et al. A case of "ifufunyane": a xhosa culture-bound syndrome. J Psychiatr Pract 2005; $11(6): 411-413$

42. Mbanga NI, Niehaus DJ, Mzamo NC, Wessels CJ, Allen A, Emsley RA et al. Attitudes towards and beliefs about schizophrenia in Xhosa families with affected probands. Curationis 2002; 25(1):69-73.

43. Sorsdahl K, Stein DJ, Grimsrud A, Seedat S, Flisher AJ, Williams DR et al. Traditional healers in the treatment of common mental disorders in South Africa. J Nerv Ment Dis 2009; 197(6):434-441.

44. Homsey J, Katabira E, Katabesi D, Mubiru F, Kwamya L, Tusaba Ceal. Evaluating herbal medicine for the management of Herpes zoster in human immunodeficiency virus-infected patients in Kampala. Uganda Journal of Alternative Complementary Medicine 2000; 6:1-2.

45. Luyckx V, Steenkamp V, Rubel J, Stewart M. Adverse effects associated with the use of South African traditional folk remedies. Central African Journal of Medicine 2004; 50:46-51

46. Jorm AF, Korten AE, Jacomb PA, Christensen H, Rodgers B, Pollitt P. "Mental health literacy": a survey of the public's ability to recognise mental disorders and their beliefs about the effectiveness of treatment. Med J Aust 1997; 166(4):182-186.

47. Bruwer B, Sorsdahl K, Harrison J, Stein DJ, Williams D, Seedat S. Barriers to mental health care and predictors of treatment dropout in the South African Stress and Health Study. Psychiatr Serv 201 1; 62 (7):774-781.

48. Hugo CJ, Boshoff DE, Traut A, Zungu-Dirwayi N, Stein DJ. Community attitudes toward and knowledge of mental illness in South Africa. Soc Psychiatry Psychiatr Epidemiol 2003; 38(12):715-719.

49. Sorsdahl KR, Stein DJ. Knowledge of and stigma associated with mental disorders in a South african community sample. J Nerv Ment Dis 2010; 198(10):742-747.

50. Sorsdahl KR, Mall S, Stein DJ, Joska JA. Perspectives towards mental illness in people living with HIVIAIDS in South Africa. AIDS Care 2010; 22(11):14181427

51. Jorm AF, Christensen H, Griffiths KM. Changes in depression awareness and attitudes in Australia: the impact of beyondblue: the national depression initiative. Aust N Z J Psychiatry 2006; 40(1):42-46.

52. Jorm AF. Mental health literacy: Empowering the community to take action for better mental health. Am Psychol 2011.

53. Thornicroft. Shunned: Discrimination against people with mental illness. London: Oxford University Press, 2006.

54. Hugo CJ, Boshoff DE, Traut A, Zungu-Dirwayi N, Stein DJ. Community attitudes toward and knowledge of mental illness in South Africa. Soc Psychiatry Psychiatr Epidemiol 2003; 38(12):715-719.

55. Mbanga NI, Niehaus DJ, Mzamo NC, Wessels CJ, Allen A, Emsley RA et al. Attitudes towards and beliefs about schizophrenia in Xhosa families with affected probands. Curationis 2002; 25(1):69-73

56. Mbanga NI, Niehaus DJ, Mzamo NC, Wessels CJ, Allen A, Emsley RA et al. Attitudes towards and beliefs about schizophrenia in Xhosa families with affected probands. Curationis 2002; 25(1):69-73.

57. Sorsdahl KR, Stein DJ. Knowledge of and stigma associated with mental disorders in a South african community sample. J Nerv Ment Dis 2010, 198(10):742-747.

58. Ganasen KA, Parker S, Hugo CJ, Stein DJ, Emsley RA, Seedat S. Mental health literacy: focus on developing countries. Afr J Psychiatry 2008; 11 (1):23-28.

59. Sorsdahl KR, Kakuma R, Wilson Z, Stein DJ. The internalized stigma experienced by members of a mental health advocacy group in South Africa. Int J Soc Psychiatry 2010

60. Kakuma R, Kleintjes S, Lund C, Drew N, Green A, Flisher AJ. Mental Health Stigma: What is being done to raise awareness and reduce stigma in South Africa? Afr J Psychiatry (Johannesbg) 2010; 13(2):116-124.

61. Robbins RN, Remien RH, Mellins CA, Joska JA, Stein DJ. Screening for HIVassociated dementia in South Africa: potentials and pitfalls of task-shifting. AIDS Patient Care STDS 201 1; 25(10):587-593

62. Muga FA, Jenkins R. Training, attitudes and practice of district health workers in Kenya. Soc Psychiatry Psychiatr Epidemiol 2008; 43(6):477-482

63. Marais A, de Villiers PJ, Moller AT, Stein DJ. Domestic violence in patients visiting general practitioners--prevalence, phenomenology, and association with psychopathology. S Afr Med J 1999; 89(6):635-640.

64. Stein DJ, Boshoff D, Abrahams FD, Traut A, Bruyn JH, van der Spuy J. Patients presenting with fresh trauma after interpersonal violence. South African Medical Journal 1997; 87:996-998.

65. Myers BJ, Pasche S, Adam M. Correlates of substance abuse treatment completion among disadvantaged communities in Cape Town, South Africa. Subst Abuse Treat Prev Policy 2010; 5:3.

66. Stein DJ, Seedat S, Emsley RA, Olley BO. HIVIAIDS in Africa--a role for the mental health practitioner? S Afr Med J 2005; 95(3):167-168.

67. Browne FA, Wechsberg WM. The intersecting risks of substance use and HIV risk among substance-using South African men and women. Curr Opin Psychiatry 2010; 23(3):205-209. 